\title{
Idiopathic Subglottic Tracheal Stenosis Misdiagnosed As Vocal Cord Dysfunction and Successfully Treated with Laser and Controlled Radial Expansion Balloon Dilation
}

\author{
Sajin M. Karakattu ${ }^{1}$, Karthik Vijayan ${ }^{1}$, Ibrahim Haddad ${ }^{2}$, Adel El Abbassi ${ }^{1}$ \\ 1. Pulmonary and Critical Care, East Tennessee State University, Johnson City, USA 2. Internal Medicine, Quillen \\ College of Medicine, East Tennessee State University, Johnson City, USA
}

Corresponding author: Sajin M. Karakattu, karakattu@mail.etsu.edu

\begin{abstract}
Idiopathic tracheal stenosis (ITS) is a rare condition, and diagnosis of exclusion should be suspected in patients with exercise intolerance, wheezing, and dyspnea on exertion with a flow-volume loop suggestive of fixed airway obstruction. We report a case of a 32-year-old asthmatic woman with an existing diagnosis of vocal cord dysfunction and previous normal CT scan of the neck. She continued to have fixed upper airway obstruction on repeated flow-volume loops with persistent wheezing and cough along with occasional stridor and hoarseness of voice despite appropriate management of her asthma. She was finally diagnosed with ITS on a repeat CT scan of the neck for which she underwent laser surgery, steroid injection, and controlled radial expansion balloon dilation with a successful reduction of stenosis. This case illustrates the importance of clinical suspicion for early diagnosis of ITS in poorly controlled asthmatic patients and the relevance of non-surgical management of this condition.
\end{abstract}

Categories: Internal Medicine, Pulmonology

Keywords: tracheal stenosis, pulmonary function test, vocal cord dysfunction

\section{Introduction}

Idiopathic tracheal stenosis (ITS) is usually misdiagnosed as asthma, which delays appropriate management and adds to the frustrations of patients. Diagnosis is based on history, neck imaging, and spirometry and confirmed with direct visualization of the stenotic segment during bronchoscopy. Treatment approaches include surgical and non-surgical options.

Received 03/29/2020 Review began 04/02/2020 Review ended 04/05/2020 Published 04/16/2020

๑) Copyright 2020 Karakattu et al. This is an open access article distributed under the terms of the Creative Commons Attribution License CC-BY 4.0., which permits unrestricted use, distribution, and reproduction in any medium, provided the original author and source are credited.

\section{Case Presentation}

A 32-year-old Caucasian woman, a lifelong non-smoker with a body mass index of 44.3, was referred to our outpatient pulmonary clinic for asthma and vocal cord dysfunction. She had complaints of cough, wheezing, and dyspnea on exertion with occasional stridor for many years for which she was on a steroid inhaler along with albuterol inhaler. She reported poor control of her symptoms and denied any history of recurrent infections, increased sputum production, hemoptysis, esophageal reflux, tracheal trauma, previous endotracheal intubation, or any inflammatory or infiltrative processes. Her erythrocyte sedimentation rate, antinuclear antibody, rheumatoid factor, anti-myeloperoxidase (MPO), anti-proteinase 3 (PR3), antiSjögren's syndrome A (SSA/Ro), anti-Sjögren Syndrome B (SSB/La), anti-Scl70, and circulating levels of alpha -1 antitrypsin were within the normal limits. She had no eosinophilia, and her IgE level was normal, along with normal immunoglobulin levels. She also had a sleep study, which was normal, and over 18 months, had four pulmonary function tests (PFTs), all of which showed an obstructive pattern with no bronchodilator response and normal diffusion capacity. Flow-volume loops showed flattening of inspiratory and expiratory maneuvers, suggestive of fixed upper airway obstruction.

Three years prior to our initial evaluation, she had a CT scan of the neck, which showed only mild prominence of parapharyngeal mucosa that appeared reactive with no other abnormalities and underwent otorhinolaryngology evaluation and was diagnosed as vocal cord dysfunction. During one of her follow-up appointments in our clinic, she endorsed new onset hoarseness of voice. Giving her new onset hoarseness of voice and multiple previous PFTs suggestive of fixed upper airway obstruction, we decided to repeat her imaging. She underwent a CT scan of the neck, which confirmed an irregularly narrowed (60\%) trachea $3 \mathrm{~cm}$ above the carina and $6 \mathrm{~cm}$ below the vocal cords with septation along the right posterior aspect of the trachea (Figure 1). 


\section{Cureus}

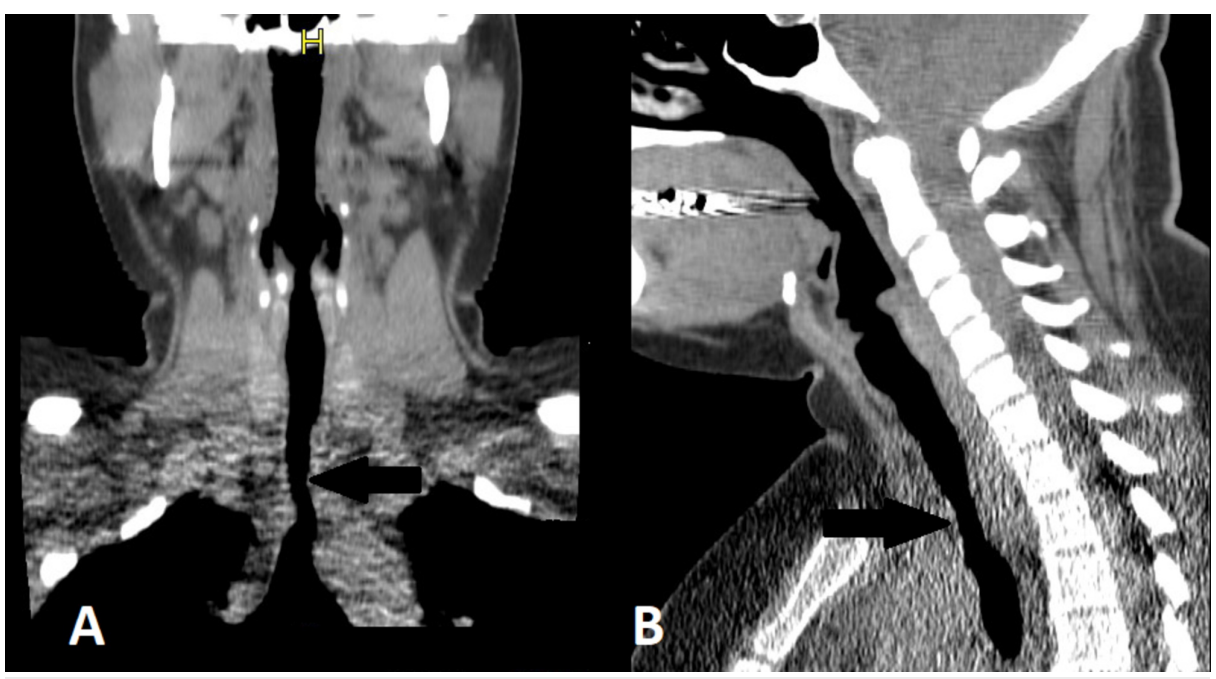

FIGURE 1: Coronal (A) and sagittal (1B) sections showing $60 \%$ tracheal narrowing approximately $6 \mathrm{~cm}$ below the vocal cords (arrows).

Subsequently, she underwent bronchoscopy that showed complex tracheal stenosis approximately $3 \mathrm{~cm}$ above the carina and extending for $4 \mathrm{~cm}$ into the trachea. It showed complex narrowing that caused significant scarring in the middle leading to a small airway on the right posterior wall of the trachea, giving an appearance of a tracheal bronchus (Figure $2 A$ ). The narrowest area was $4 \mathrm{~cm}$ above the carina. She had laser surgery followed by controlled radial expansion (CRE) balloon dilation of tracheal stenosis, which reached an internal diameter of $14 \mathrm{~mm}$ with complete resolution of stenosis confirmed with follow-up bronchoscopy (Figure $2 B$ ). She followed up in our clinic a few weeks later and endorsed complete resolution of wheezing, dyspnea, hoarseness of voice, and cough. However, her flow-volume loop continued to show fixed airway obstruction even after six months of her procedure.

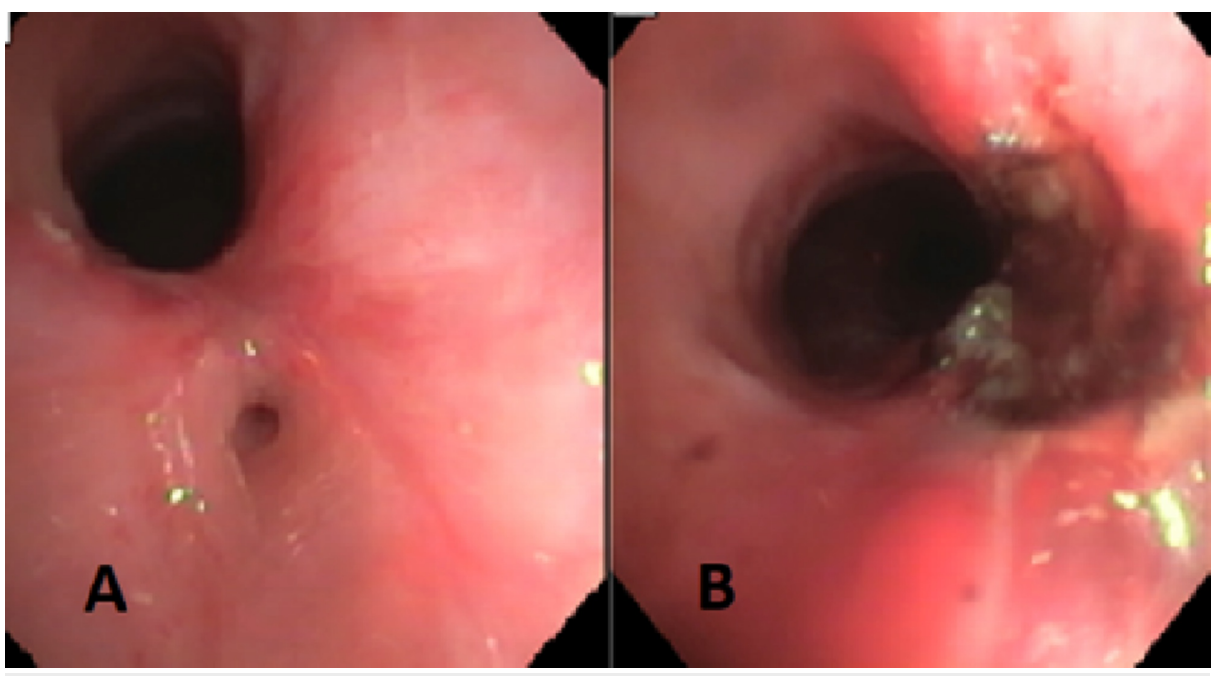

FIGURE 2: Complex narrowing that caused a significant scarring and a small airway (A). Post laser laster therapy and controlled radial expansion balloon dilation with a relief of stenosis (B).

\section{Discussion}

ITS represents a diagnosis of exclusion and occurs exclusively in middle-aged women, mostly postmenopausal [1-3]. It produces stenosis of 1-3 cm, which is densely collagenous, and unaccompanied by systemic disease [4-6]. An association between gastroesophageal reflux disease and laryngotracheal stenosis has been found. However, a definite conclusion regarding its role has not yet been reached, especially since the stenosis does not typically progress $[6,7]$. The female predominance suggests hormonal etiology of the disease. One of the postulated mechanisms is the absence of estrogen receptors at the site of stenosis, which leads to an increase in fibroblast growth factor resulting in the formation of the stenotic lesion; however, 
investigations failed to show direct correlation, and the cause of the disease has remained elusive. Persistent mucosal inflammation and altered microbial composition termed "microbiota dysbiosis" are the hallmark of the disease; however, the relationship between tracheal microbiota dysbiosis and ITS is not well understood $[8,9]$.

Tracheal stenosis could be due to extrinsic (direct external compression as in mediastinal malignancy) or intrinsic causes. Etiologies of intrinsic stenosis include autoimmune conditions (systemic lupus erythematosus, sarcoidosis, amyloidosis, granulomatosis with polyangiitis, polychondritis, and Wegener's granulomatosis), inhalational burn, infectious processes (rhinolaryngoscleroma, tuberculosis, bacterial tracheitis, diphtheria, and histoplasmosis), or idiopathic as in our patient [8]. The diagnosis is based on the combination of findings on history, physical exam, and diagnostic testing. Presenting symptoms are shortness of breath, cough, stridor, hoarseness, and wheezing, and patients are often misdiagnosed with asthma with minimal responsiveness to steroid and bronchodilator inhalers. Spirometry, CT scan, and bronchoscopy are necessary modalities to diagnose this disorder [10]. The flow-volume loop on spirometry reveals flattening of both the inspiratory and expiratory loops, despite numerical data showing no definite obstruction. CT scan of the neck will show the extent and severity of stenosis, but confirmation of the diagnosis requires direct visualization with bronchoscopy.

There is some controversy regarding the most favored approach for the treatment of ITS, with balloon dilation being the most conservative approach [11]. Other modalities such as airway stenting, laser treatment (Nd-YAG laser surgery via a fibreoptic bronchoscope), endoluminal spray cryotherapy, tailored cricoplasty, and surgical reconstruction or resection are all valid options [12-15]. Approximately $47 \%-71 \%$ of the patients with a non-malignant disease may be managed with balloon dilation alone, although the recurrence rate after balloon dilation is higher than other approaches [16]. In cases where ITS involves only the upper trachea, segmental resection with end-to-end anastomosis can be performed. It is usually done as one-stage resection and reconstruction, most often including a portion of the lower larynx with more than $90 \%$ of patients preserving their voice quality [17]. In a case series of 263 patients diagnosed with idiopathic subglottic stenosis and treated with laryngotracheal resection and reconstruction, the overall success rate was reported to be $91 \%$, considering all forms of recurrences [18]. Medical treatment with agents such as mitomycin $\mathrm{C}$ and steroid injections are used as adjunctive treatments.

\section{Conclusions}

ITS is a rare condition, and a diagnosis of exclusion should be suspected in patients who present with unexplained wheezing, hoarseness, dyspnea on exertion, and cough along with flow-volume loops suggestive of fixed upper airway obstruction. It may mimic symptoms of asthma and, in our case, an existing diagnosis of vocal cord dysfunction, which in turn can lead to delay in diagnosis and definitive management. Despite growing evidence of lesser recurrence rates in favor of surgical correction, we believe that there is still a significant role of minimally invasive measures in the treatment of the stenosis. However, it is agreeable that repeated laser and CRE balloon dilations would render the patient an unsuitable candidate for definitive surgical management. Patients may continue to have flow-volume loops suggestive of fixed upper airway obstruction despite clinical improvement, which makes it more challenging to follow up these patients for relapse. More studies regarding the resolution of the fixed defect in the flow-volume loop after laser surgery and balloon dilation are needed.

\section{Additional Information \\ Disclosures}

Human subjects: Consent was obtained by all participants in this study. Conflicts of interest: In compliance with the ICMJE uniform disclosure form, all authors declare the following: Payment/services info: All authors have declared that no financial support was received from any organization for the submitted work. Financial relationships: All authors have declared that they have no financial relationships at present or within the previous three years with any organizations that might have an interest in the submitted work. Other relationships: All authors have declared that there are no other relationships or activities that could appear to have influenced the submitted work.

\section{References}

1. Hatta C, Terada T, Kakibuchi M, Ogasawara H, Nakasho K, Sakagami M: A case of idiopathic tracheal stenosis. Auris Nasus Larynx. 2003, 30:435-438.

2. Harries PG, Mason PS, Ramsay AD, Carruth JA: Idiopathic tracheal stenoses. J Laryngol Otol. 1996, 110:973975. 10.1017/s0022215100135480

3. Brandenburg JH: Idiopathic subglottic stenosis. Trans Am Acad Ophthalmol Otolaryngol. 1972, 76:14021406.

4. Mark EJ, Meng F, Kradin RL, Mathisen DJ, Matsubara O: Idiopathic tracheal stenosis: a clinicopathologic study of 63 cases and comparison of the pathology with chondromalacia. Am J Surg Pathol. 2008, 32:11381143. 10.1097/PAS.0b013e3181648d4a

5. Grillo HC, Mark EJ, Mathisen DJ, Wain JC: Idiopathic laryngotracheal stenosis and its management. Ann Thorac Surg. 1993, 56:80-87. 10.1016/0003-4975(93)90406-8

6. Dedo HH, Catten MD: Idiopathic progressive subglottic stenosis: findings and treatment in 52 patients . Ann 
Otol Rhinol Laryngol. 2001, 110:305-311. 10.1177/000348940111000403

7. Rossi C, Colombari F, Guembarowsky AL, Ferreira Filho OF, Thomson JC: Idiopathic tracheal stenosis. A report of four cases. J Bras Pneumol. 2007, 33:101-104. 10.1590/s1806-37132007000100018

8. Gelbard A, Katsantonis NG, Mizuta M, et al.: Molecular analysis of idiopathic subglottic stenosis for Mycobacterium species. Laryngoscope. 2017, 127:179-185. 10.1002/lary.26097

9. Poetker DM, Etterna SL, BLumin JH, Toohill RJ, Merati AL: Association of airway abnormalities and risk factors in 37 subglottic stenosis patients. Otolaryngol Head Neck Surg. 2006, 135:434-437. 10.1016/j.otohns.2006.04.013

10. Bhalla M, Grillo HC, McLoud TC, Shepard JO, Weber AL, Mark EJ: Idiopathic laryngotracheal stenosis: radiologic findings. J Roentgenol. 1993, 161:515-517. 10.2214/ajr.161.3.8352095

11. Solly WR, O'Connell RJ, Lee HJ, Sterman DH, Haas AR: Diagnosis of idiopathic tracheal stenosis and treatment with papillotome electrocautery and balloon bronchoplasty. Respir Care. 2011, 56:1617-1620. 10.4187/respcare.01143

12. Mehta AC, Lee FY, Cordasco EM, Kirby T, Eliachar I, De Boer G: Concentric tracheal and subglottic stenosis: management using the Nd-YAG laser for mucosal sparing followed by gentle dilatation. Chest. 1993, 104:673-677. 10.1378/chest.104.3.673

13. Bhora FY, Ayub A, Forleiter CM, et al.: Treatment of benign tracheal stenosis using endoluminal spray cryotherapy. JAMA Otolaryngol Head Neck Surg. 2016, 142:1082-1087. 10.1001/jamaoto.2016.2018

14. Liberman M, Mathisen DJ: Tailored cricoplasty: an improved modification for reconstruction in subglottic tracheal stenosis. J Thorac Cardiovasc Surg. 2009, 137:573-579. 10.1016/j.jtcvs.2008.11.020

15. Navani N, Costello D, Brown JM, Sandhu G, Janes SM, George J: A rare asthma mimic exposed by basic physiology. QJM. 2011, 104:59-60. 10.1093/qjmed/hcq054

16. McArdle J, Gildea T, Mehta A: Balloon bronchoplasty its indication, benefits and complications . J Bronch. 2005, 12:123-127. 10.1097/01.laboratory.0000159783.34078.3d

17. Ashiku SK, Kuzucu A, Grillo HC, et al.: Idiopathic laryngotracheal stenosis: effective definitive treatment by laryngotracheal resection. J Thorac Cardiovasc Surg. 2004, 127:99-107. 10.1016/j.jtcvs.2002.11.001

18. Wang H, Wright CD, Wain JC, Ott HC, Mathisen DJ: Idiopathic subglottic stenosis: factors affecting outcome after single-stage repair. Ann Thorac Surg. 2015, 100:1804-1811. 10.1016/j.athoracsur.2015.05.079 